\title{
Continuous measurements of net production over a shallow reef community using a modified Eulerian approach
}

\author{
James L. Falter, ${ }^{1}$ Ryan J. Lowe, ${ }^{2}$ Marlin J. Atkinson, ${ }^{1}$ Stephen G. Monismith, ${ }^{3}$ \\ and Daniel W. Schar ${ }^{1}$ \\ Received 27 November 2007; revised 7 February 2008; accepted 28 February 2008; published 24 July 2008.
}

[1] We made continuous measurements of the flux of dissolved oxygen over an algal-dominated reef flat community on the Kaneohe Bay Barrier Reef, Hawaii as a proxy for the net production $(N P)$ of organic carbon. Fluxes were calculated from measurements of dissolved oxygen and current profiles taken from moored oxygen sensors and acoustic Doppler current profilers (ADCPs) located at points defining the vertices of a triangular control volume $250 \mathrm{~m}$ in length on each side. Surface cruciform drifters as well as dye patches were tracked across the control volume to get independent measurements of Lagrangian currents. While the dye patch speeds were highly correlated with the depth-averaged current speeds calculated from ADCP data on a 1:1 basis $\left(r^{2}=0.86, n=24\right)$, drifter speeds exceeded both dye and calculated current speeds by $30-100 \%$ on average. Measurements of dissolved oxygen sampled within the dye patches as it propagated across the study site were used to calculate $N P$ following a Lagrangian approach. Lagrangian estimates of $N P$ were highly correlated with Eulerian estimates of $N P$ on a $1: 1$ basis $\left(r^{2}=0.81, n=7\right)$. Ratios of community production and community respiration varied from 0.7 to 1.4 on a daily basis, but approached a value of 1.0 when integrated over the entire data record.

Citation: Falter, J. L., R. J. Lowe, M. J. Atkinson, S. G. Monismith, and D. W. Schar (2008), Continuous measurements of net production over a shallow reef community using a modified Eulerian approach, J. Geophys. Res., 113, C07035, doi:10.1029/2007JC004663.

\section{Introduction}

[2] The production and respiration of organic carbon are the two most fundamental pathways by which mass and energy move through any community or ecosystem. The rate of community organic carbon production via photosynthesis represents the capacity of a community to produce new biomass or biochemical energy from inorganic precursors, while rates of community respiration represent the cumulative metabolic demand of a community for this biochemical energy. Differences between rates of production and respiration indicate how dependent a living community is on external sources of organic carbon (allochthonous) versus what it can produce on its own (autochthonous) via photo- or chemosynthesis. In coral reef communities, the photosynthetic production of organic carbon is also an importance force driving the precipitation of calcium carbonate by coral and algae [Al-Horani et al., 2003; Chalker, 1981; Gattuso et al., 1996; Goreau, 1959].

\footnotetext{
${ }^{1}$ Hawaii Institute of Marine Biology, University of Hawaii, Kaneohe, Hawaii, USA.

${ }^{2}$ School for Environmental Systems Engineering, University of Western Australia, Perth, WA, Australia.

${ }^{3}$ Environmental Fluid Mechanics Laboratory, Stanford University, Stanford, California, USA.
}

Copyright 2008 by the American Geophysical Union. 0148-0227/08/2007JC004663\$09.00
[3] Rates of community calcification and organic carbon production are highest in shallow reef communities $(<10 \mathrm{~m})$ due to the mutual dependencies of these processes on light [Barnes and Devereux, 1984; Lough and Barnes, 2000]. Consequently, rates of reef accretion tend to be greatest at their margins where the benthos is very close to the sea surface. It is this rate of accretion which ultimately determine whether the growth of a coral reef can keep up with rising sea level. Shallow reef communities are often particularly subject to highly variable environmental conditions given that they are exposed to the greatest light, wind, wave, and tidal energy. They grow on top of carbonate platforms which separate offshore coastal waters from inshore lagoons. The advection and mixing of water from each of these sources due to natural circulation patterns can result in rapid changes in overall water "quality" such as salinity, temperature, nutrient concentration, organic particle abundance, suspended sediment, and optical clarity. In addition, shallow reef flats can be subject to additional elevations in temperature due to solar heating of shallow water columns experiencing limited exchange with cooler water located either offshore or in deeper lagoons. Coral communities living in shallow water are particularly susceptible to combined thermal and light stress which can lead to bleaching and possible mortality [Anthony et al., 2007; Hoegh-Guldberg, 1999; Hughes et al., 2003; Lesser, 1996]. 
For all of these reasons, shallow reef communities will likely be the most susceptible to environmental variation due to climate change.

[4] Rates of cumulative daily community gross photosynthetic production $\left(P\right.$ in mmol $\left.\mathrm{C} \mathrm{m}^{-2} \mathrm{~d}^{-1}\right)$ and cumulative daily community respiration $\left(R\right.$ in mmol $\left.\mathrm{C} \mathrm{m}^{-2} \mathrm{~d}^{-1}\right)$ have been measured over shallow reef communities for more than half a century [Kinsey, 1985; Odum and Odum, 1955; Sargent and Austin, 1949]. Historically, prior studies have employed a Lagrangian approach for measuring net production (termed "flow respirometry") whereby parcels of water were followed across the reef with changes in the dissolved oxygen and/or carbonate parameters of the water being measured to estimate the net fluxes of carbon to or from the reef community. These measurements were laborintensive, requiring measurements at different times of day and night over the course of several weeks just to generate a single diurnal curve of Net Production necessary for deriving estimates of $P$ and $R$ [Smith and Marsh, 1973; Smith and Kinsey, 1978]. Integration of diurnal Net Production (NP in mmol C m${ }^{-2} \mathrm{~h}^{-1}$ ) curves to get estimates of $P$ and $R$ was challenging and subjective given the degree of scatter often present in the data [see, e.g., Smith and Marsh, 1973; Atkinson and Grigg, 1984]. Part of this scatter was likely due to variations in current trajectories such that individual measurements of $N P$ were often made over different regions of the reef. This is particularly problematic given the spatially patchy nature of shallow reef communities which often vary abruptly from areas of metabolically active coral and algae to more metabolically quiescent sands. Scatter in early diurnal $N P$ curves likely further resulted from shortterm variations in incident light due to water clarity and cloud cover [Anthony et al., 2004]. Some investigators simply assumed that the diurnal NP curve could be represented by a specific sinusoidal curve reflecting changes in incident light under absolutely clear skies [Kinsey, 1978, 1985], an assumption which does not hold for many reef systems.

[5] Gattuso et al. [1993, 1996] demonstrated that NP by a Moorea reef flat community could be functionally related to the amount of light incident to the air-sea interface. Using these functional relationships, they developed a creative approach for dealing with the problem of integrating diurnal $N P$ curves: generating curves of $N P$ versus incident light and then using this relationship in conjunction with continuous measurements of incident light to generate continuous measurements of NP. This represented a marked improvement over traditional methods of flow respirometry. However, the use of a single representative light curve generated from several weeks of data inherently assumes a single average respiration rate for the entire period, thus neglecting any natural variations in $R$ which is necessary for assessing natural variations in $P$ [Falter et al., 2001]. Thus this approach still represented both an indirect and integrated method for measuring fluxes of organic carbon to and from reef communities by using light as a single proxy variable. Furthermore, there are additional problems in measuring $N P$ at night using a Lagrangian approach given inaccuracies in the measurements of cross-reef transport by drifters and the intractability of following dye patches.

[6] In the present paper we present an Eulerian approach for making continuous measurements of $N P$ over a coral reef community using fixed moorings of current meters and dissolved oxygen sensors. This approach allows $P$ and $R$ to be measured over the same exact reef community on a dayto-day basis with little attention to maintenance and for an indefinite length of time. Unlike field enclosures or benthic chambers, the approach is noninvasive and does not restrict the movement of water, materials, or organisms in and out of the reef community at any time. However, to be used properly it requires some careful examination of the hydrodynamic processes governing the transport of water across the reef community in question.

\section{Methods}

\subsection{Site Description}

[7] Kaneohe Bay is located on the northeast, or windward, side of the island of Oahu, Hawaii. The Kaneohe Bay Barrier Reef (KBBR) is approximately $2-\mathrm{km}$ wide and 10-km long, separating the interior bay from the adjacent coastal ocean (Figure 1A). Trade winds blow primarily out of the northeast 4-7 $\mathrm{m} \mathrm{s}^{-1}$ during most of the year. These winds generate trade-wind waves $6-10 \mathrm{~s}$ in period and typically $1-2 \mathrm{~m}$ in height which impinge on the KBBR. During the winter months (October-March), ocean swells 10-16 s in period generated north to northwest of the main Hawaiian islands can wrap around the northern coast of Oahu and impinge upon the KBBR as well, adding to the shoreward flux of wave energy. Our study area sits on the KBBR flat near the island of Kapapa and just shoreward of the surf zone (Figure 1B). This section of the reef flat is $1.5-2 \mathrm{~m}$ deep and is dominated by the growth of turf algae and macro-algae of the genera Sargassum, Microdictyon, Acanthophora, Halimeda, and Turbinaria on a lithified reef surface. There is less than a few percent coral cover within the study area. Waves incident to the KBBR generally drive the movement of water across the reef flat and through the study area, while the tides vary $\pm 0.4 \mathrm{~m}$ in height on average.

\subsection{Eulerian Estimates of Transport and NP}

[8] Within the study area, a control volume was defined by an equilateral triangle roughly $250 \mathrm{~m}$ on each side (Figure 1B). While past open control volumes have been designed around the shape of a box [e.g., Genin et al., 2002], we chose a triangle so as to employ the least amount of instrumentation necessary to enclose a finite volume of water thus minimizing costs. At each vertex of the triangle both current profiles and dissolved oxygen concentration were measured. Net organic carbon fluxes were calculated from changes in dissolved oxygen through the stoichiometry of photosynthetic carbon fixation and its reverse reaction: respiration

$$
N P=J_{O 2} / P Q
$$

where $J_{O 2}$ is the net flux of oxygen into and out of the benthos and $P Q$ is the photosynthetic quotient equal to the moles of dissolved oxygen produced per mole of carbon dioxide fixed via photosynthesis, or conversely, as to the moles of oxygen consumed per mole of carbon dioxide released via respiration. The latter condition assumes that both photosynthesis and respiration follow the same 


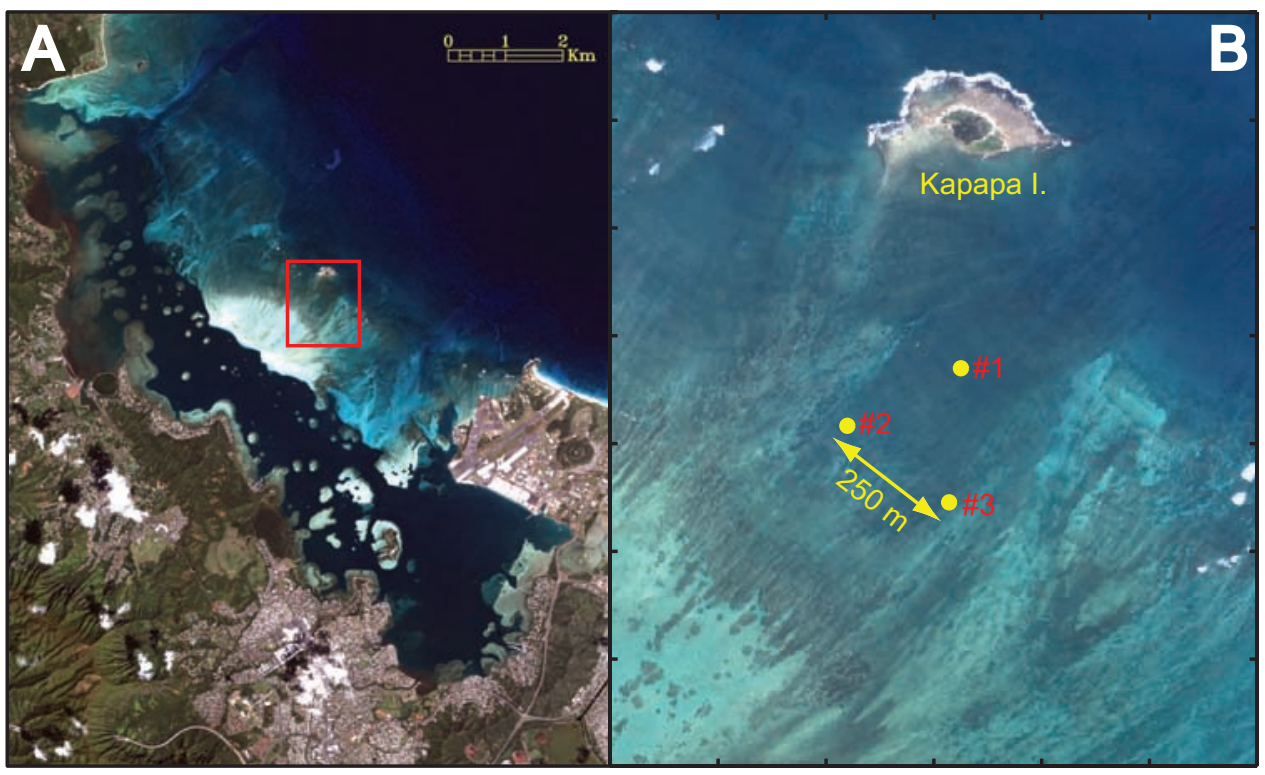

Figure 1. (A) Quickbird image of Kaneohe Bay courtesy of Digitalglobe (C) with the study area bounded by a red box. (B) Close-up image of the study area showing the location of the control volume vertices.

reaction stoichiometry. Prior measurements indicate that $P Q$ for reef communities are typically very close to one $(1.05 \pm$ 0.1, [Carpenter and Williams, 2007; Smith and Marsh, 1973]) indicating that oxygen fluxes can be generally equated to carbon fluxes on a mole per mole basis with few exceptions. Nonetheless, in the present paper we report all measurements of $N P$ in mmol $\mathrm{O}_{2} \mathrm{~m}^{-2} \mathrm{~h}^{-1}$ since minor deviations in the photosynthetic quotient is not a subject of this paper.

\subsubsection{Integral Approach}

[9] One way to calculate $N P$ from in situ measurements of transport and dissolved oxygen is by defining a control volume and subsequently estimating the nonconservative flux in the scalar quantity of interest [Genin et al., 2002]. For our purposes, this is accomplished by summing: (1) changes in the dissolved oxygen content within the control volume (equation (2)), (2) the flux of dissolved oxygen across each of the faces of the control surface, and (3) the flux of oxygen across the air-sea interface, i.e.,

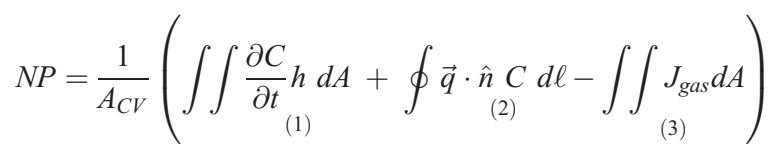

where $A_{C V}$ is the plan area covered by the control volume, $\vec{q}$ is the depth-integrated Lagrangian transport, i.e., the sum of Eulerian and Stokes drift transports [Monismith and Fong, 2004; Plumb, 1979], $\hat{n}$ is the unit surface normal vector defining each face of the control volume, $C$ represents the concentration of dissolved oxygen, and $h$ is the local depth of the water column. Equation (2) has been simplified by assuming that the water column is vertically well-mixed, an assumption that is supported by observations made in this area on several occasions prior to this study (data not shown). Thus for a control volume defined with measurements made at the three vertices of a triangle, equation (2) can be discretized as

$$
N P=\left\langle\frac{\partial C}{\partial t} \cdot h\right\rangle+\frac{1}{A_{C V}} \sum_{i=1}^{3} \vec{q}_{i} \cdot \hat{n}_{i} C_{i} l_{i}-\left\langle J_{g a s}\right\rangle
$$

where \langle\rangle represents a spatial average over the control volume and $l$ is the length of each side $i$ of the control surface. $J_{\text {gas }}$ is the net flux of oxygen across the air-sea interface defined to be positive into the control volume. The method of calculation represented by equation (3) will herein be referred to as the "integral" control volume approach. It is important to note that equation (3) requires that the measured flows be nondivergent, i.e., that

$$
\sum_{i=1}^{3} \vec{q}_{i} \cdot \hat{n}_{i} l_{i}=0
$$

\subsubsection{Differential Approach}

[10] Alternatively, fluxes of dissolved oxygen within the control volume can be calculated using a differential form of the vertically integrated advection-dispersion-reaction equation which is composed of a local accumulation term, an advective flux term, a dispersive flux term, $N P$ and an airsea gas flux

$$
\underset{\substack{l o c a l}}{h \frac{\partial C}{\partial t}}+\underset{\text { advection }}{\vec{q} \cdot \vec{\nabla}_{h} C}=\underset{\text { dispersion }}{K \nabla_{h}^{2} C}+N P+J_{\text {gas }}
$$

where $K$ is the horizontal dispersion coefficient. In the present study we assume that the dispersion term is very small in comparison with the other terms and can be 
neglected; an assumption which we validate later. Equation (5) must also be discretized to reflect the sampling of concentrations and flows at the control volume vertices as well as averaging of the relevant physical and chemical quantities over the finite area covered by the control volume, i.e.:

$$
N P=\left\langle\frac{\partial C}{\partial t} \cdot h\right\rangle+\left\langle q_{x}\right\rangle \cdot\left\langle\frac{\partial C}{\partial x}\right\rangle+\left\langle q_{y}\right\rangle \cdot\left\langle\frac{\partial C}{\partial y}\right\rangle-\left\langle J_{\text {gas }}\right\rangle
$$

where $x$ and $y$ represent derivatives or components in the cross- and along-reef directions, respectively. The method of calculation shown in equation (6) differs only from equation (3) in terms of how the advective component of the nonconservative flux is represented by the advective terms in both equations. The method of calculation given by equation (6) is herein termed the "differential" control volume approach.

[11] The cross-reef and along-reef gradients in dissolved oxygen, $\left\langle\frac{\partial C}{\partial x}\right\rangle$ and $\left\langle\frac{\partial C}{\partial y}\right\rangle$ were estimated by first defining two vector quantities:

$$
\begin{aligned}
& \vec{B}_{12} \equiv \Delta x_{12} \hat{i}+\Delta y_{12} \hat{j}+\Delta C_{12} \hat{c} \\
& \vec{B}_{13} \equiv \Delta x_{13} \hat{i}+\Delta y_{13} \hat{j}+\Delta C_{13} \hat{c}
\end{aligned}
$$

where $\Delta x_{i j}, \Delta y_{i j}, \Delta C_{i j}$ each represent differences between stations $i$ and $j$ in the cross-reef position, along-reef position, and concentration, respectively. Concentrations measured at vertices \#1, \#2, and \#3 (Figure 1B) define a surface over $x$ and $y$ whose normal vector can be calculated by taking the following cross product

$$
\vec{N}=\vec{B}_{12} \times \vec{B}_{13}=n_{x} \hat{i}+n_{y} \hat{j}+n_{C} \hat{c}
$$

This vector defines a plane having the functional form:

$$
f(x, y, C)=n_{x} x+n_{y} y+n_{c} C=\text { constant. }
$$

Gradients of concentration on this surface can then be calculated according to the following:

$$
\left\langle\frac{\partial C}{\partial x}\right\rangle=\frac{-n_{x}}{n_{C}} \quad \text { and } \quad\left\langle\frac{\partial C}{\partial y}\right\rangle=\frac{-n_{y}}{n_{C}} .
$$

The advantages of this approach is that (1) it measures spatial gradients along both horizontal axes with only three mooring sites, (2) it does not require that the shape of control volume satisfies any particular symmetry, and (3) it is independent of the orientation of the control volume vertices. This spatial averaging was performed by interpolating the measured quantities onto $N$ equally spaced grid points over a triangular surface whose vertices were $(x, y$, $C),(x, y, h),(x, y, q)$, etc. and then taking the spatial mean.

[12] $J_{\text {gas }}$ is conventionally parameterized by the following linear equation [Broecker and Peng, 1982]:

$$
J_{g a s}=k_{O 2}\left(C_{e q}-C\right)
$$

where $k_{\mathrm{O} 2}$ is the gas exchange constant and $C_{e q}$ represents the concentration of dissolved oxygen in equilibrium with the atmosphere at a given temperature and salinity [Garcia and Gordon, 1992]. Gas exchange coefficients for a gas with a Schmidt number (Sc) of $600\left(k_{600}\right.$ in $\left.\mathrm{cm} \mathrm{h}^{-1}\right)$ were estimated from wind speed using a quadratic relationship published by Ho et al. [2006]

$$
k_{600}=0.266 U_{10}^{2}
$$

where $U_{10}$ is the wind speed at $10 \mathrm{~m}$. The exchange coefficient for dissolved oxygen is calculated according to

$$
k_{O 2}=\left(\frac{600}{\mathrm{Sc}_{O 2}}\right)^{-n} k_{600}
$$

where $\mathrm{Sc}_{\mathrm{O} 2}$ is the Schmidt number for dissolved oxygen, and $n=0.5$ for wavy surfaces [Jahne and Haussacker, 1998].

[13] Nighttime community respiration rates $\left(R_{\text {dark }}\right.$ in mmol m $\mathrm{m}^{-2} \mathrm{~h}^{-1}$ ) were calculated by averaging NP between sunset and sunrise

$$
R_{\text {dark }}=-\frac{1}{\tau_{\text {dark }}} \int_{\text {sunset }}^{\text {sunrise }} N P(t) d t
$$

where $\tau_{\text {dark }}$ is the time elapsed between sunset and sunrise. Daily integrated community respiration rates $(R$ in mmol $\mathrm{m}^{-2} \mathrm{~d}^{-1}$ ) for a given day were calculated as the average of $R_{\text {dark }}$ from preceding and following nights

$$
R^{i}=24 \frac{\left(R_{\text {dark }}^{i}+R_{\text {dark }}^{i-1}\right)}{2}
$$

Daily integrated Net Community Production (NCP in mmol $\mathrm{m}^{-2} \mathrm{~d}^{-1}$ ) was calculated by direct integration of $N P$ from midnight to midnight over a given day (similar to equation (14)). Daily integrated Gross Primary Production ( GPP in mmol m-2 $\mathrm{d}^{-1}$ ) was calculated simply as the sum of $R$ and $N C P$ since by definition: $N C P \equiv P-R$.

\subsubsection{Measurements}

[14] Dissolved oxygen and temperature were measured at each vertex of the control volume with InSitu Troll 9000 loggers equipped with Aanderaa RDO dissolved oxygen optodes sampling every $5 \mathrm{~min}$ without interruption. All three sensors were calibrated in the laboratory $( \pm 2 \mathrm{uM})$ before deployment over a range of 20 to $350 \mu \mathrm{M}$ at $25^{\circ} \mathrm{C}$ and a salinity of 35 against direct analysis by Winkler titration $( \pm 0.5 \mathrm{uM})$. Once the dissolved oxygen sensors were deployed on the reef flat, duplicate water samples were collected every other day using a 2-L Van Dorn bottle and immediately fixed for analysis by Winkler titration. Dissolved oxygen concentrations determined from these samples were used to correct for instrument drift by linear interpolation of the difference between sensor DO values and those determined by titration. Salinity was measured three times an hour in the center of the control volume (\#5, Figure 1B) using a Seabird Electronics SBE 26 wavegauge equipped with a SBE4 conductivity sensor.

[15] Vertical profiles of current speed and direction along with wave properties were measured at each vertex of the control volume using three RD Instruments $1200 \mathrm{kHz}$ acoustic Doppler current profilers (ADCP). The ADCPs 
were programmed in mode 12 to sample velocity and pressure at $1 \mathrm{~Hz}$ in $10 \mathrm{~min}$ bursts every $20 \mathrm{~min}$. To generate vertical profiles of mean currents, 3-D velocities were measured every $5 \mathrm{~cm}$ from $50 \mathrm{~cm}$ above the bottom to $30 \mathrm{~cm}$ below mean sea level and averaged over each 10-min burst. The resulting mean profiles were then integrated to calculate the total 2-D Eulerian transport $\left(\mathrm{m}^{3} \mathrm{~s}^{-1} \mathrm{~m}^{-1}\right), q_{E}$, for each burst. The magnitude of the Stokes transport was estimated from the wave height spectra $(S)$ following the approach of Kenyon [1969] where the different frequency components $(f)$ are integrated, i.e.

$$
q_{S}=\int_{0}^{\infty} \frac{g k}{\omega} S(f) d f
$$

where $k$ is the wave number, and $\omega$ is the angular wave frequency. The relationship between $\omega$ and $k$ are given by the dispersion relationship

$$
\omega=g k \tanh (k h)
$$

Wave height spectra were calculated from pressure data measured synoptically with the current profiles by each of the ADCPs. Pressure data were analyzed by dividing each burst into 16 sections of equal length, each with $50 \%$ overlap, applying a Hanning window to the segments, and computing spectra. These were converted to one-dimensional $S$ using linear wave theory, from which we calculated significant wave heights as $H_{s}=4 \sqrt{m_{0}}$, where $m_{0}$ is the zeroth moment of $S$ based on the energy between 2 and $30 \mathrm{~s}$ (this generally contained $>99 \%$ of the total wave energy). Although there is some minor refraction of the wavefronts as they move across the reef flat [Falter et al., 2004; Lowe et al., 2005], for simplicity we assumed that all of the Stokes transport was in the cross-reef direction at each vertex of the control volume $\left(230^{\circ}\right)$. This is consistent with predictions of wave direction from a numerical wave transformation model (SWAN, WL|Delft Hydraulics) run previously over a range of incident wave conditions (data not shown).

[16] The above instrument arrays were deployed from 1 to 18 December 2006 (17 d). During these periods, hourly mean wind speeds were measured at the nearby Marine Corp Base Hawaii located on the Mokapu peninsula which forms the SE boundary of Kaneohe Bay (Figure 1A). Measurements taken during a prior study showed that wind speeds on average at Kapapa Island were only a few percent faster than at the Mokapu peninsula while wind direction differed by less than $5^{\circ}$ with both being highly correlated $\left(r^{2}=0.76, n=630\right.$; Lowe et al. submitted). Offshore wave heights were measured with a Datawell directional wave buoy located $\sim 8 \mathrm{~km}$ southeast of the Mokapu peninsula $\left(21^{\circ} 25^{\prime} \mathrm{N} 157^{\circ} 41^{\prime} \mathrm{W}\right)$, maintained by the University of Hawaii Sea Level Center (www.uhslc.soest.hawaii.edu) as part of the Coastal Data Information Program (www.cdip. ucsd.edu). Unfortunately, one of the oxygen sensors was physically damaged in the middle of the deployment, likely due to handling of the instrument by local fishermen. Thus no dissolved oxygen and oxygen flux data is available between 7 and 13 December.

\subsection{Lagrangian Estimates of Transport and $N P$}

[17] Lagrangian transport was measured by following both cruciform drifters $80-\mathrm{cm}$ tall and $60-\mathrm{cm}$ wide, and parcels of water seeded with visible concentrations of fluorescein dye using a WAAS-enabled hand-held GPS $( \pm 5 \mathrm{~m})$ and small boat to record their location as they traversed $\sim 150-300 \mathrm{~m}$ across the control volume. The geometry of the drifters followed a conventional design [e.g., Austin and Atkinson, 2004]. Net Production was also calculated from the sum of the depth-integrated material derivative and the gas flux computed in a Lagrangian reference frame

$$
N P_{L}=h \underset{\text { material }}{h t}-J_{\text {gas }}
$$

The material derivative can be estimated by taking the difference between the initial and final oxygen concentrations in a particular water parcel, multiplying it by the average depth over which the water parcel had traversed, and then dividing this quantity by the amount of time over which the change in oxygen concentration had been measured. Gas fluxes across the air-water interface was calculated according to equations (11) through (13). Estimates of $N P_{L}$, however, were made by following only the dye patches and not the drifters. Duplicate water samples were collected at roughly three equally spaced locations across the control volume for later analysis by Winkler titration. The material derivative was calculated using only the initial and final samples to match the spatial scale at which measurements of $N P$ were being made within the control volume. Saturation concentrations of dissolved oxygen were calculated from recorded temperature and salinity data, and gas exchange velocities were estimated from recorded wind data (see section 2.2). The depth of the water parcel was calculated using a geo-referenced map of high-resolution bathymetry $( \pm 0.1 \mathrm{~m}$; Laser Imaging Detection and Radar using a SHOALS sensor operated by the Army Corps of Engineers) and corrected for tidal modulation using pressure data from the three ADCPs and the wavegauge.

\subsection{Dispersion}

[18] In addition to advection by mean currents, vertical shear and turbulence will lead to dispersive fluxes or changes in concentration as shown in equation (5). To examine horizontal dispersion within the control volume, and thus to quantify this error, two cruciform drifters were deployed $\sim 1-\mathrm{m}$ apart and tracked individually. Dispersion coefficients $(K)$ were then calculated from the drifters according to

$$
K \approx \frac{\Delta \sigma(t)^{2}}{2 \Delta t}
$$

where $\sigma(t)$ is equal to the deviation of each drifter $i$ from the centroid at time

$$
\sigma(t)=\frac{1}{N-1} \sum_{i=1}^{N}\left(x_{i}(t)-\bar{x}(t)\right)^{2}
$$



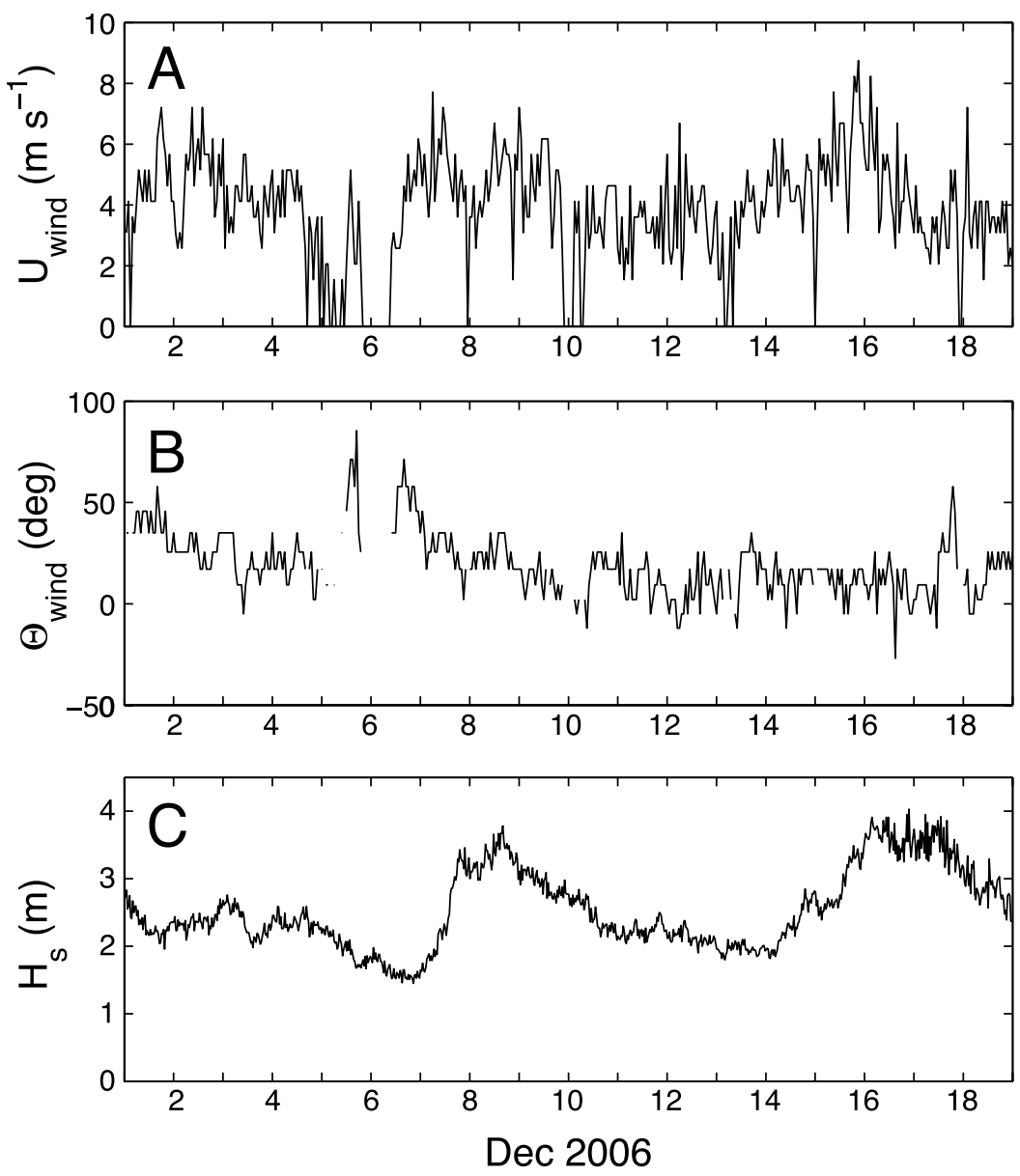

Figure 2. (A) Wind speed and (B) direction collected on the Mokapu peninsula as a proxy for wind speed and direction at Kapapa Island in December 2006 (see text for details). (C) Significant wave height off the Mokapu peninsula over the same period.

[List et al., 1990]. Although it is generally better to use many drifters to get statistically robust estimates of $K$, we will show that our multiple estimates of $K$ obtained with only two drifters can be used to simply demonstrate that rates of horizontal dispersion are very small. For the case of only two drifters, equations (19) and (20) can be combined and simplified to give

$$
K_{d r} \approx \frac{\Delta \ell_{d r}^{2}}{4 \Delta t}
$$

where $\ell_{d r}$ is the separation distance in $\mathrm{m}$ between the two drifters. The above equation assumes that horizontal dispersion on the reef flat is isotropic. Another approach used to examine horizontal dispersion was to measure the change in the length of the axes of the dye patch in the streamwise direction $\left(\ell_{S}\right)$ as well as transverse to the dominant current $\left(\ell_{t}\right)$. Dispersion coefficients for each axis ( $K_{s}$ and $K_{t}$ ) could then be estimated according to equation (21). The three dissolved oxygen samples taken for Lagrangian calculations of $N P$ were used to estimate the second spatial derivative with respect to oxygen concentration in the direction of dye parcel propagation $\left(\partial^{2} C / \partial s^{2}\right)$ by computing the central finite difference. The nonconservative flux of dissolved oxygen due to dispersion $\left(J_{D}\right)$ can be calculated according to

$$
J_{D}=-h K_{s} \frac{\partial^{2} C}{\partial s^{2}}
$$

where $s$ denotes the position along a current streamline. Because we are tracking a water mass $30-40$ min periods to estimate $\partial^{2} C / \partial s^{2}$, we are implicitly assuming that $\partial^{2} C / \partial s^{2}$ did not change substantially over the period of measurement.

\section{Results}

\subsection{General Conditions}

[19] Wind speeds during the deployment varied between 0 and $8 \mathrm{~m} \mathrm{~s}^{-1}$ (Figure 2A) with $95 \%$ of the data spanning directions of -5 to $60^{\circ}$ reflecting the predominantly $\mathrm{NE}$ direction of the trade winds (Figure 2B). Offshore significant wave heights varied from typical values of $1.5 \mathrm{~m}$ to near annual maxima of just under $4 \mathrm{~m}$. Nonetheless, offshore significant wave heights averaged $2.5 \mathrm{~m}$ over the deployment period, or $0.5 \mathrm{~m}$ higher than the perennial average of around $2 \mathrm{~m}$ [Falter et al., 2004]. The significant heights of residual waves emerging from the surf zone and 


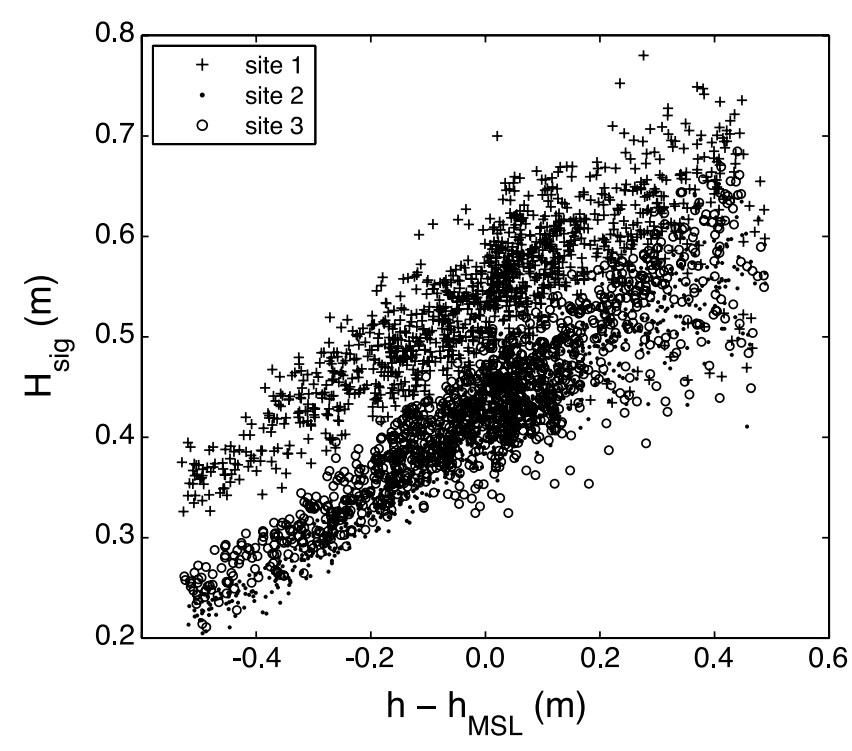

Figure 3. Significant height of waves measured at sites $\# 1, \# 2$, and $\# 3$ versus depth relative to mean sea level.

propagating through the control volume on the reef flat varied between 0.2 and $0.7 \mathrm{~m}$ and were strongly modulated by the tide (Figure 3) but nearly independent of offshore wave heights. Dissolved oxygen concentrations exhibited normal diel-type fluctuations of 40 to $150 \mathrm{uM}$ (Figure 4).
All three oxygen sensors drifted 1 to $3 \mathrm{uM} \mathrm{d}^{-1}$ but were never more than 5 to $20 \mathrm{uM}$ from their initial calibration. Water temperature and salinity varied between 23.6 to $26.1^{\circ} \mathrm{C}$ and 34.6 to 35.0 , respectively (data not shown).

[20] Depth-averaged currents generally varied between 5 and $15 \mathrm{~cm} \mathrm{~s}^{-1}$ (Figure 5A), rising and falling with offshore wave heights, behavior common to many reefs [Callaghan et al., 2006; Hearn and Parker, 1988; Symonds et al., 1995; J. L. Hench et al., Episodic circulation and exchange in a wave-driven coral reef and lagoon system, manuscript in preparation, 2008]. Depth-averaged Stokes drift varied between 0.5 and $3 \mathrm{~cm} \mathrm{~s}^{-1}$ indicating that wave-driven Eulerian currents dominated total Lagrangian transport for most of the study period. The ratio of Stokes transport $\left(q_{S}\right)$ to total transport $(q)$ exhibited a Rayleigh-like distribution (Figure 6). This ratio decreased when wave-driven currents increased owing to wave heights on the reef flat being nearly invariant with time once tidal fluctuations are removed.

[21] Current speeds measured with both drifters and dye patches $U_{L}$ were positively correlated with computed mean Eulerian plus Stokes current speeds, $U_{E+S}$ (Figure 7A), however, drifter current speeds were significantly higher than computed Eulerian plus Stokes speeds by $4-5 \mathrm{~cm} \mathrm{~s}^{-1}$ $(p<0.01)$. Dye-patch current speeds were not significantly different from Eulerian plus Stokes speeds and differed on average by only $1.5 \mathrm{~cm} \mathrm{~s}^{-1}$. The mean absolute difference between dye-patch current trajectories and Eulerian plus
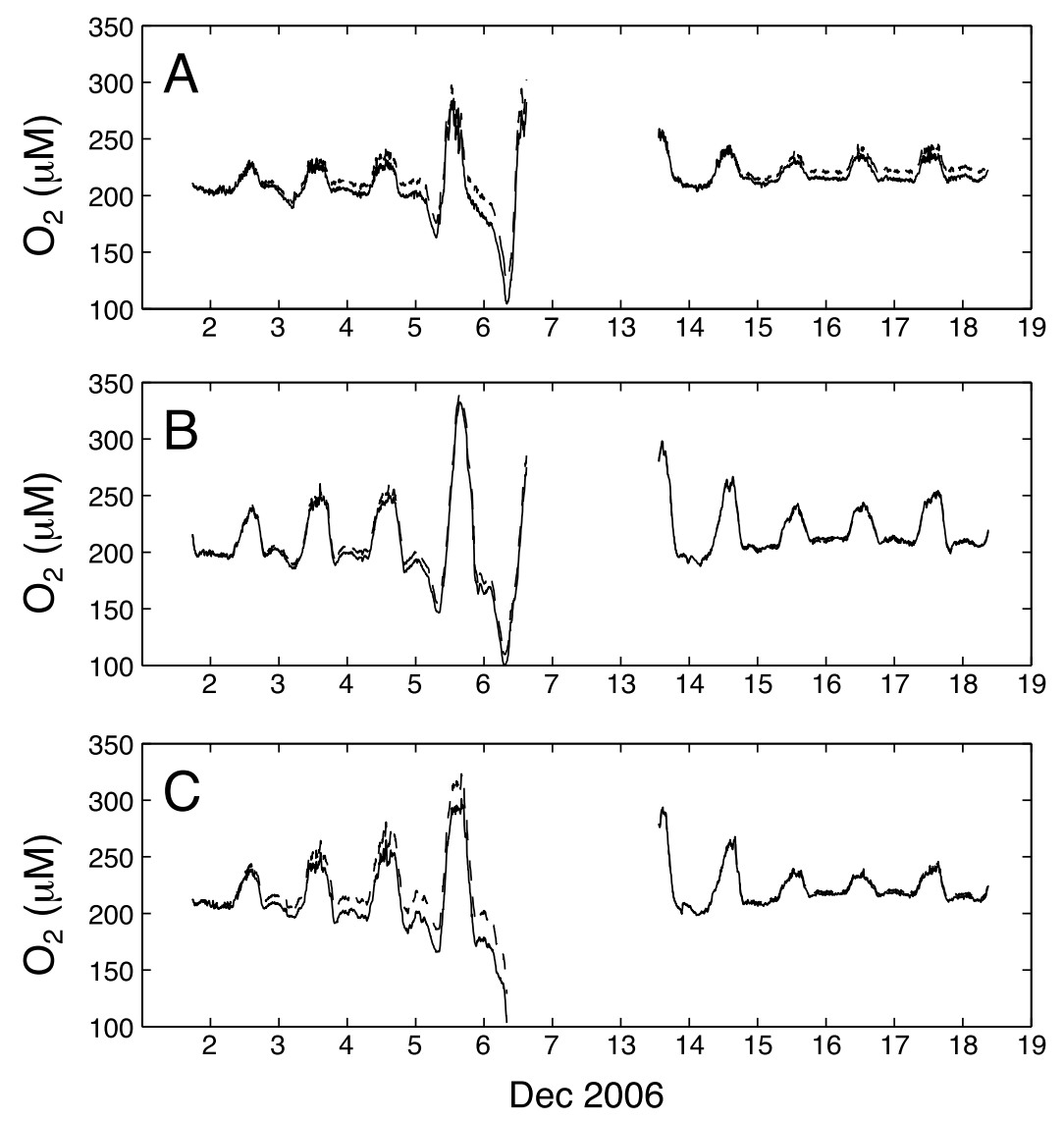

Figure 4. Dissolved oxygen concentrations at site \#1 (A), \#2 (B), and \#3 (C) corrected (solid) and uncorrected (dashed) for drift. The break in time is due to failure of one of the sensors. 

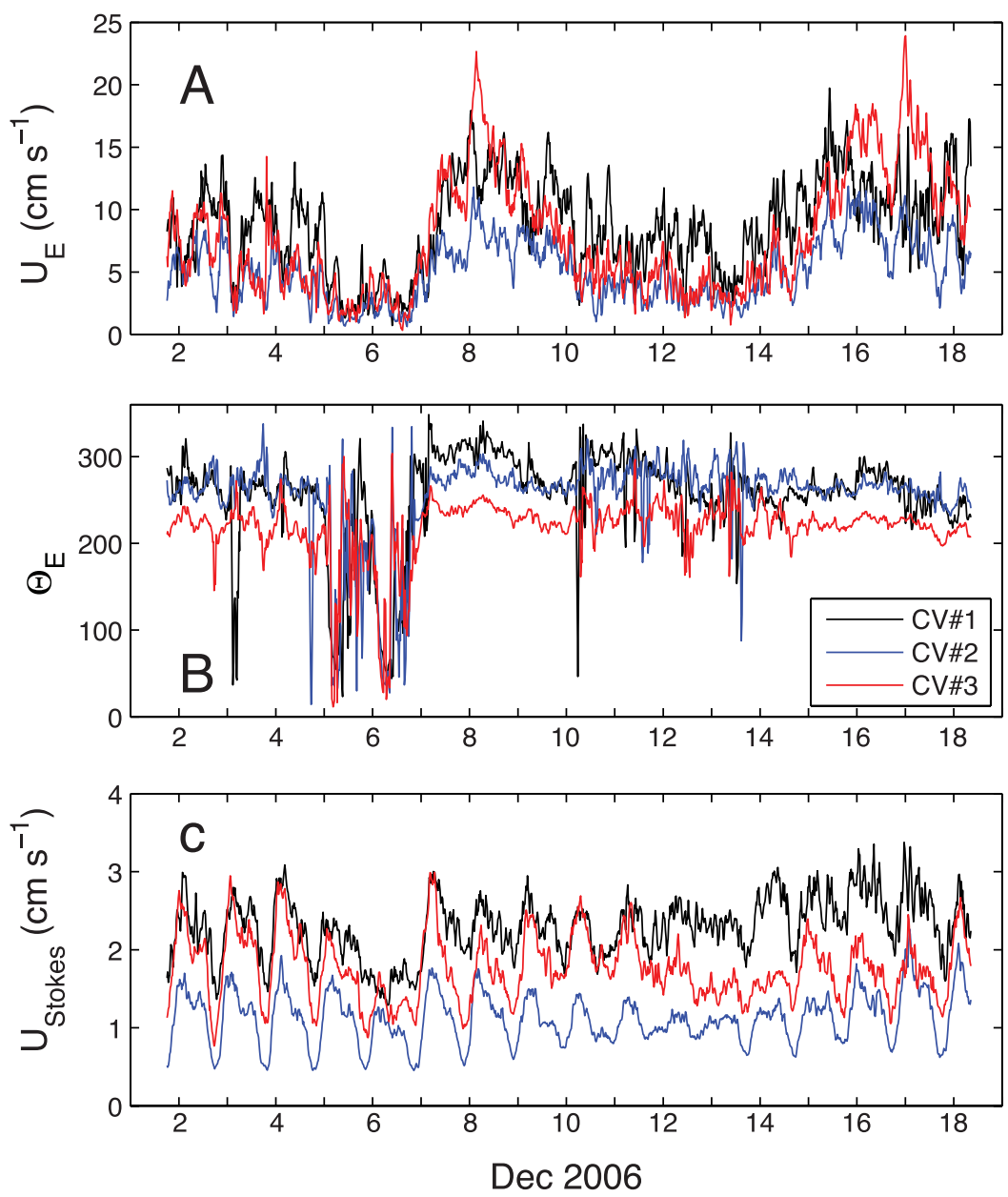

Figure 5. Depth-averaged current speed (A) and direction (B) at site $\# 1, \# 2$, and \#3 derived from ADCP measurements. (C) Depth-averaged Stokes drift at sites \#1, \#2, and \#3. The legend in (Figure 5B) applies for all plots.

Stokes trajectories $\left(\overline{\left|\theta_{\text {dye }}-\theta_{E+S}\right|}\right)$ was $13^{\circ}$ while between drifter current trajectories and Eulerian plus Stokes current trajectories $\left(\left|\theta_{\text {drift }}-\theta_{E+S}\right|\right)$ was $15^{\circ}$. This indicates little difference between the trajectories of the drifters or dye patches and the Eulerian plus Stokes current directions.

[22] Dispersion coefficients calculated from four separate deployments of two drifters $\left(K_{d r}\right)$ were $0.01,0.01,0.03$, and $0.04 \mathrm{~m}^{2} \mathrm{~s}^{-1}$. Dye patches spread from an initially symmetric patch size of $\sim 2 \mathrm{~m}$ across to between $30-40 \mathrm{~m}$ across in the direction of the current $\left(\ell_{s}\right)$ and only 5-6 m across along the transverse axis $\left(\ell_{t}\right)$ over a $\sim 15$-min period before needing to be reseeded with additional dye. This kind of anisotropic distortion of the dye patch is consistent with shear flow dispersion [Fischer, 1979]. While $\ell_{s}$ could be reliably measured with a WAAS-enabled GPS, $\ell_{t}$ could only be estimated visually due to its short length $(<5 \mathrm{~m})$. While only approximate, our visually based estimate of $K_{t} \sim 0.01 \mathrm{~m}^{2}$ $\mathrm{s}^{-1}$ is consistent with measured values of $K_{d r}$. Values of $K_{s}$ on the other hand were generally of magnitude greater than either $K_{d r}$ or $K_{t}$, varying between 0.14 and $0.91 \mathrm{~m}^{2} \mathrm{~s}^{-1}$ (Table 1). Concurrent measurements of $\partial^{2} C / \partial s^{2}$ in the direction of dye patch propagation varied between $0.08 \times$ $10^{-3}$ and $-3.0 \times 10^{-3} \mathrm{mmol} \mathrm{m}^{-5}$ (Table 1).

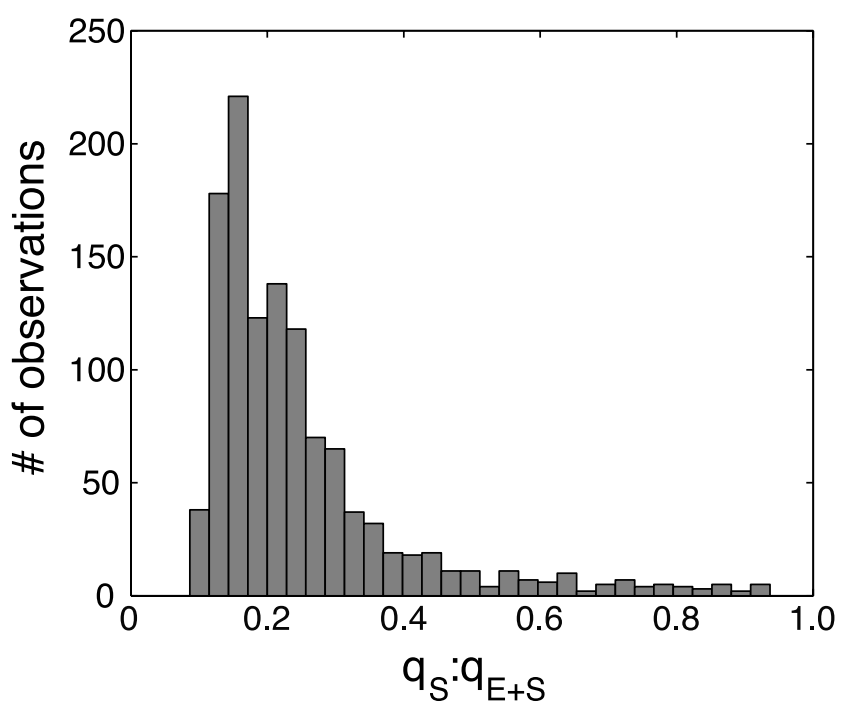

Figure 6. Distribution in the ratio of Stokes transport to total transport. 

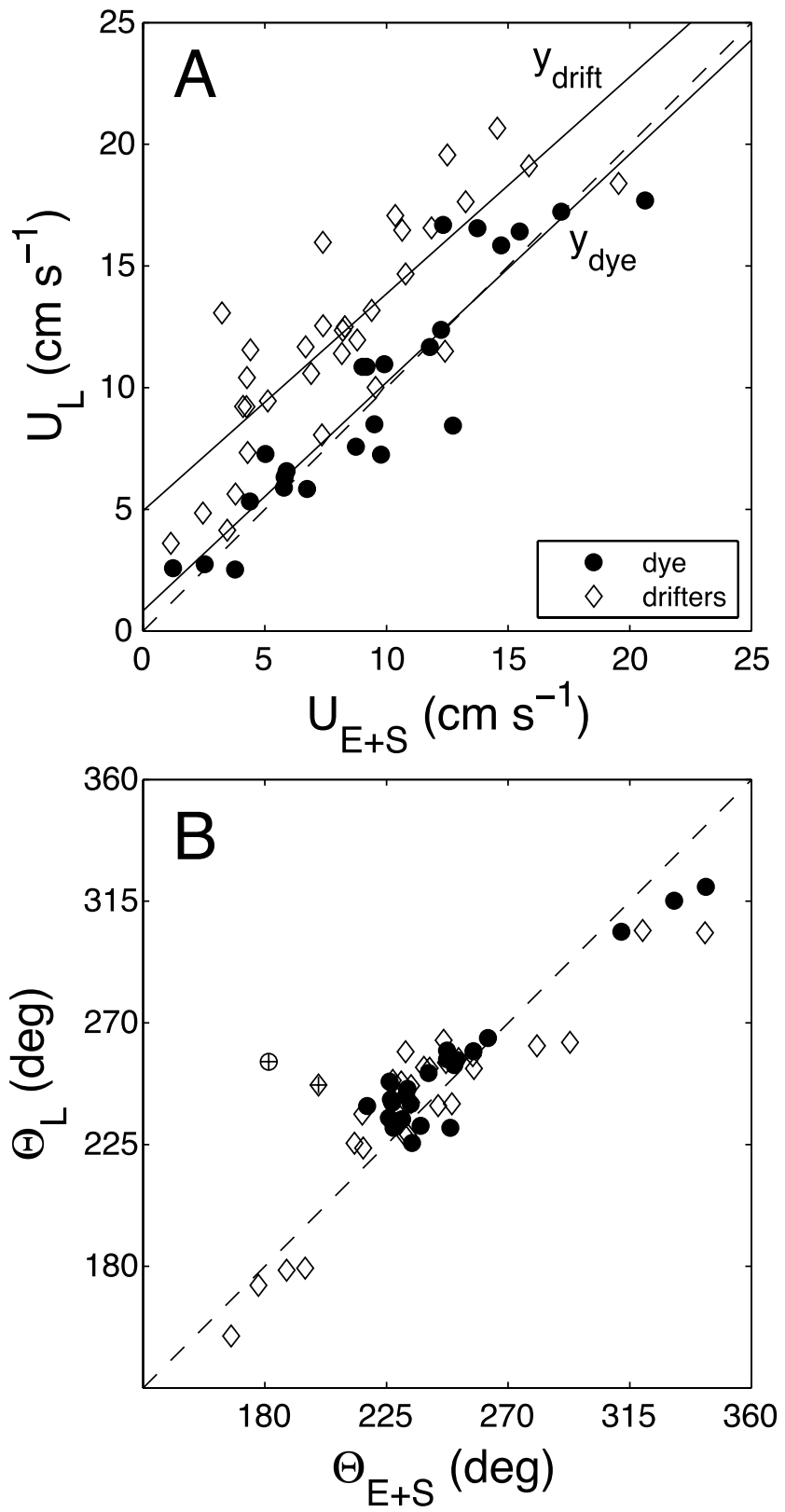

Figure 7. (A) Lagrangian current speeds $\left(U_{L}\right)$ as measured with dye and surface drifters versus speeds computed from current profiles and calculated Stokes drift $\left(U_{E+S}\right)$. Regression equation for the drifters is $y_{\text {drift }}=0.9 x+5, r^{2}=$ $0.70, n=34$ and for the dye is $y_{d y e}=0.9 x+1, r^{2}=0.86, n=$ 24. The dashed line represents a 1:1 ratio. (B) Lagrangian current directions $\left(\theta_{L}\right)$ from drifters $\left(r^{2}=0.81, n=34\right)$ and dye patches $\left(r^{2}=0.90, n=24\right)$ versus directions computed from current profiles and calculated Stokes drift $\left(\theta_{E+S}\right)$. The crossed symbols have been omitted from the regression calculation due to currents being less than $1 \mathrm{~cm} \mathrm{~s}^{-1}$. The dashed line represents a 1:1 ratio.

\subsection{Eulerian Oxygen Fluxes}

[23] Given that depth-averaged currents $\left(U_{L}\right)$ were typically $\sim 5-15 \mathrm{~cm} \mathrm{~s}^{-1}$, it would generally take $30-80 \mathrm{~min}$ for a water parcel to traverse the entire control volume. There-
Table 1. ${ }^{2} C / \partial s^{2}, K_{s}$, and $J_{D}$ Derived From Lagrangian Measurements ${ }^{\mathrm{a}}$

\begin{tabular}{cccc}
\hline $\begin{array}{c}\text { Day in } \\
\text { December }\end{array}$ & $\partial^{2} \mathrm{C} / \partial s^{2} \times 10^{-3} \mathrm{mmol} \mathrm{m}^{-5}$ & $K_{s}, \mathrm{~m}^{2} \mathrm{~s}^{-1}$ & $\begin{array}{c}J_{D}, \\
\mathrm{mmol} \mathrm{m}^{-2} \mathrm{~h}^{-1}\end{array}$ \\
\hline 5 & -3.04 & 0.14 & 2.9 \\
8 & N/A & 0.13 & $n a$ \\
13 & -1.16 & 0.13 & 1.0 \\
14 & 0.16 & 0.34 & -0.4 \\
14 & -0.16 & 0.23 & 0.2 \\
14 & 0.29 & 0.08 & -0.2 \\
17 & 0.08 & 0.83 & -0.4 \\
17 & 0.19 & 0.91 & -1.2 \\
Ave & -0.52 & 0.35 & 0.3 \\
\hline
\end{tabular}

${ }^{\mathrm{a}} \mathrm{See}$ text for details.

fore calculations of all oxygen fluxes and $N P$ were binned into 1-h intervals to reflect the natural integration time of the control volume with regard to changes in net production. Oxygen gas exchange coefficients varied between 0 and $20 \mathrm{~cm} \mathrm{~h}^{-1}$, leading to estimated gas fluxes generally between -1 and $+5 \mathrm{mmol} \mathrm{O}_{2} \mathrm{~m}^{-2} \mathrm{~h}^{-1}$ over the course of the deployment (Figure 8). Local changes in oxygen concentration within the control volume $\left(h^{\partial C} / \partial t\right)$ varied between -50 and $+50 \mathrm{mmol} \mathrm{m}^{-2} \mathrm{~h}^{-1}$ (Figure 9A), whereas advective oxygen fluxes calculated using the differential approach $\left(\vec{q} \cdot \vec{\nabla}_{h} C\right)$ were between -40 and $+40 \mathrm{mmol} \mathrm{m}^{-2} \mathrm{~h}^{-1}$ for each axis (cross-reef and along-reef, Figure 9A). Advective oxygen fluxes calculated using the integral approach gave values of between -400 and $+800 \mathrm{mmol} \mathrm{m} \mathrm{m}^{-2} \mathrm{~h}^{-1}$ (Figure 9B) leading to unreasonable estimates of $N P$ (not shown), evidently a consequence of the fact that the sum of the flows into and out of the control volume was not zero
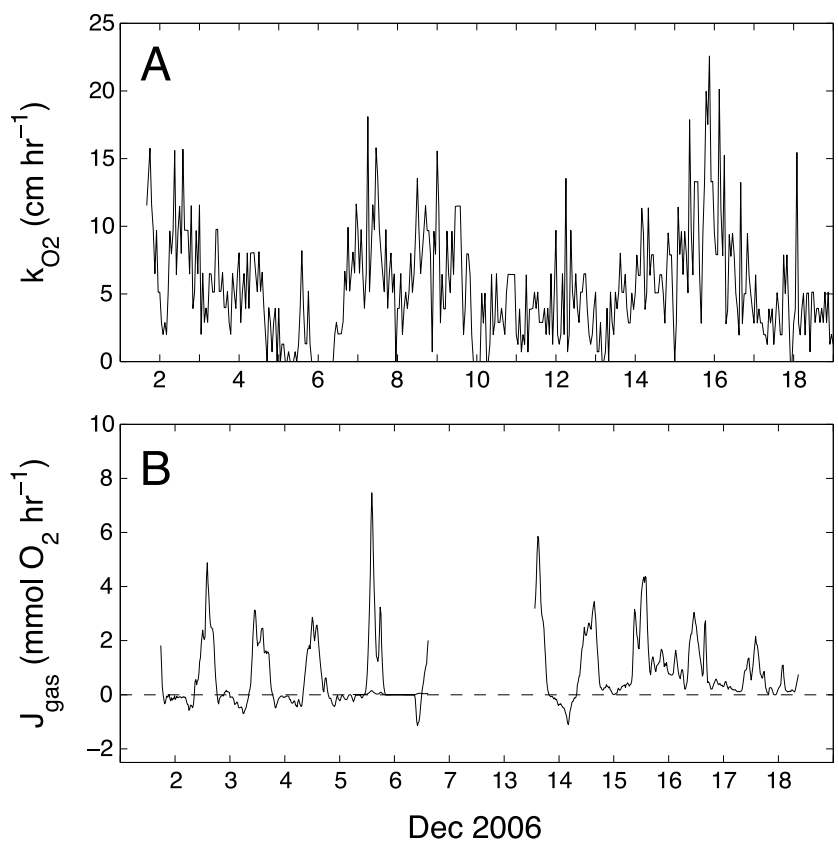

Figure 8. (A) Estimated dissolved oxygen exchange coefficient. (B) Estimated dissolved oxygen fluxes across the air-sea interface. Positive values represent the net flux of oxygen out of the water. The break in the $x$ axis is due to failure of one of the dissolved oxygen sensors. 

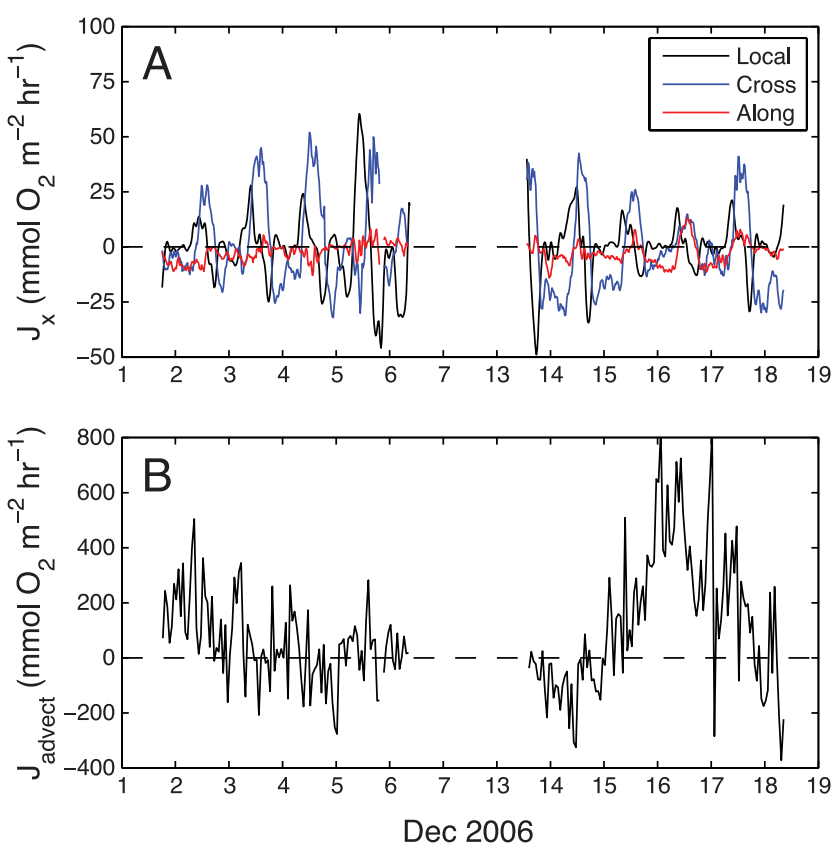

Figure 9. (A) Calculated local, cross-reef, and along-reef fluxes of dissolved oxygen using the differential approach. (B) Calculated total advective flux (cross + along) of dissolved oxygen using the integral approach.

(i.e., see equation (4)). Therefore we did not pursue any further analysis of $N P$ calculated from the integral approach. The root-mean square values of the gas, local, and total differential advective terms were $1.4,15.2$ and $22.0 \mathrm{mmol}$ $\mathrm{m}^{-2} \mathrm{~h}^{-1}$, respectively, indicating that the advective term consistently made the largest contribution to calculated $N P$ and that the gas flux term was a very minor contributor. The sum of all the dissolved oxygen fluxes using the differential approach resulted in $N P$ varying from -40 to $75 \mathrm{mmol} \mathrm{m}^{-2}$ $\mathrm{h}^{-1}$ (Figure 10). Likewise, $P, R$, and $N C P$ calculated from $N P$ using the differential approach varied between 250 and $660 \mathrm{mmol} \mathrm{O} \mathrm{m}^{-2}$, between 330 and $650 \mathrm{mmol} \mathrm{O}_{2} \mathrm{~m}^{-2}$, and between -200 and $+190 \mathrm{mmol} \mathrm{O}_{2} \mathrm{~m}^{-2}$, respectively (Table 2).

[24] Rates of instrument drift were nominal $\left(1-3 \mathrm{uM} \mathrm{d}^{-1}\right)$ in terms of the magnitude of instantaneous measurements $(150-300 \mu \mathrm{M})$. However, this type of nominal drift over the course of a 5-d deployment led to differences between actual and sensor-predicted concentrations of -2 to $+20 \mathrm{uM}$. Sensor drift tended to be monotonic such that deviations of sensor-predicted oxygen concentrations from actual concentrations were not erratic. The overwhelmingly dominant contributor to errors in calculations of $N P$ was in the uncertainty in estimates of $\vec{\nabla}_{h} C$ due to an error in $\Delta C$ of $\sim 3 \mathrm{uM}$. Maximum daytime and nighttime differences in dissolved oxygen concentration varied between 20 and $50 \mathrm{uM}$. The root-mean squared uncertainties in the gas, advective, and local terms were $\pm 0.1, \pm 8$, and $\pm 1 \mathrm{mmol} \mathrm{m}^{-2}$ $\mathrm{h}^{-1}$. Therefore we estimate uncertainties ( \pm standard error) in hourly estimates of $N P$ to be between \pm 2 and $\pm 10 \mathrm{mmol}$ $\mathrm{m}^{-2} \mathrm{~h}^{-1}$, depending upon the conditions. These uncertainties in hourly $N P$ translate into uncertainties in $P, R$, and $N C P$ of between 30 and 60,20 and 50, and 10 and $40 \mathrm{mmol}$ $\mathrm{m}^{-2} \mathrm{~d}^{-1}$, respectively (Table 2 ).

\subsection{Lagrangian Oxygen Fluxes}

[25] Net Production calculated from Lagrangian measurements following the dye patches were in close agreement with estimates made from Eulerian calculations of $N P$ using the differential approach $\left(r^{2}=0.81, n=7\right.$, Figures 10 and 11). Uncertainty in calculations of Lagrangian $N P$ was due to uncertainty in both the depth of the water column $( \pm 0.1 \mathrm{~m})$ as well as in the concentration differences between samples, and were comparable to uncertainties in Eulerian $N P$ during the times of measurements (mean error = $\pm 4 \mathrm{mmol} \mathrm{m}^{-2} \mathrm{~h}^{-1}$ for both). Observed dispersive oxygen fluxes $\left(J_{D}\right)$ were generally only $\sim 1 \mathrm{mmol} \mathrm{m}^{-2} \mathrm{~h}^{-1}$ and could be safely neglected from calculations of either Lagrangian or Eulerian NP (Table 1).

\section{Discussion}

[26] Stokes drift generally made a lesser contribution to the total transport across the reef than the Eulerian waveand tidally-driven flows. Neglecting Stokes drift, however, would have resulted in relatively large uncertainties in estimates of the total transport across the control volume during periods when these Eulerian currents were low (Figure 3). Since waves on the Kaneohe reef flat are not strictly long, the Stokes drift velocity near the water surface will be greater than the average, $q_{S} / h$, suggesting that drifter trajectories should move faster in the shoreward direction than would be inferred from either the dye patch $\left(U_{d y}\right)$ or the computed depth-averaged current speed $\left(U_{E+S}\right)$, since they sample the flow in the top $\sim 0.8 \mathrm{~m}$ of the water column. In addition to Stokes drift, surfing of the drifter in the waves could also have biased drifter-based estimates of depthaverage currents in the direction of wave propagation, however, at no time did the breaking zone reach the region encompassed by the control volume. Regardless, the direction of wave propagation is nearly constant in time since it is primarily controlled by the water depth over the shallow reef flat [Lowe et al., 2005]. However, there was only a shoreward deflection of $20^{\circ}-30^{\circ}$ even when the predominant current direction was mostly in the alongshore direction $\left(\theta_{L}>270^{\circ}\right.$, Figure 7). This suggests that while wave action contributed to the difference between observed $U_{d y}$ and $U_{E+S}$, it was not the dominant mechanism.

[27] There was no significant correlation between drifter trajectory and wind direction $(r=0.13, p<0.5, n=34$; Figure 12). Thus the effects of windage on the drifters or wind stress on the upper water column were likely minor. Therefore the best explanation for the difference between $U_{d r}$ and $U_{E+S}$ would be velocity shear in the mean current

Table 2. $P, R$, and $N C P$ in $\mathrm{mmol} \mathrm{O}_{2} \mathrm{~m}^{-2} \mathrm{~d}^{-1}( \pm 1$ s.e. $)$

\begin{tabular}{cccc}
\hline Day in Dec & $P$ & $R$ & $N C P$ \\
\hline 2 & $250(40)$ & $360(30)$ & $-110(20)$ \\
3 & $500(30)$ & $370(30)$ & $130(20)$ \\
4 & $520(30)$ & $430(20)$ & $90(20)$ \\
5 & $660(20)$ & $460(10)$ & $190(10)$ \\
Ave & 480 & 405 & +75 \\
14 & $450(40)$ & $650(30)$ & $-200(20)$ \\
15 & $350(50)$ & $430(40)$ & $-80(30)$ \\
16 & $320(60)$ & $330(50)$ & $-10(30)$ \\
17 & $470(50)$ & $450(40)$ & $30(30)$ \\
Ave & 400 & 465 & -65 \\
\hline
\end{tabular}




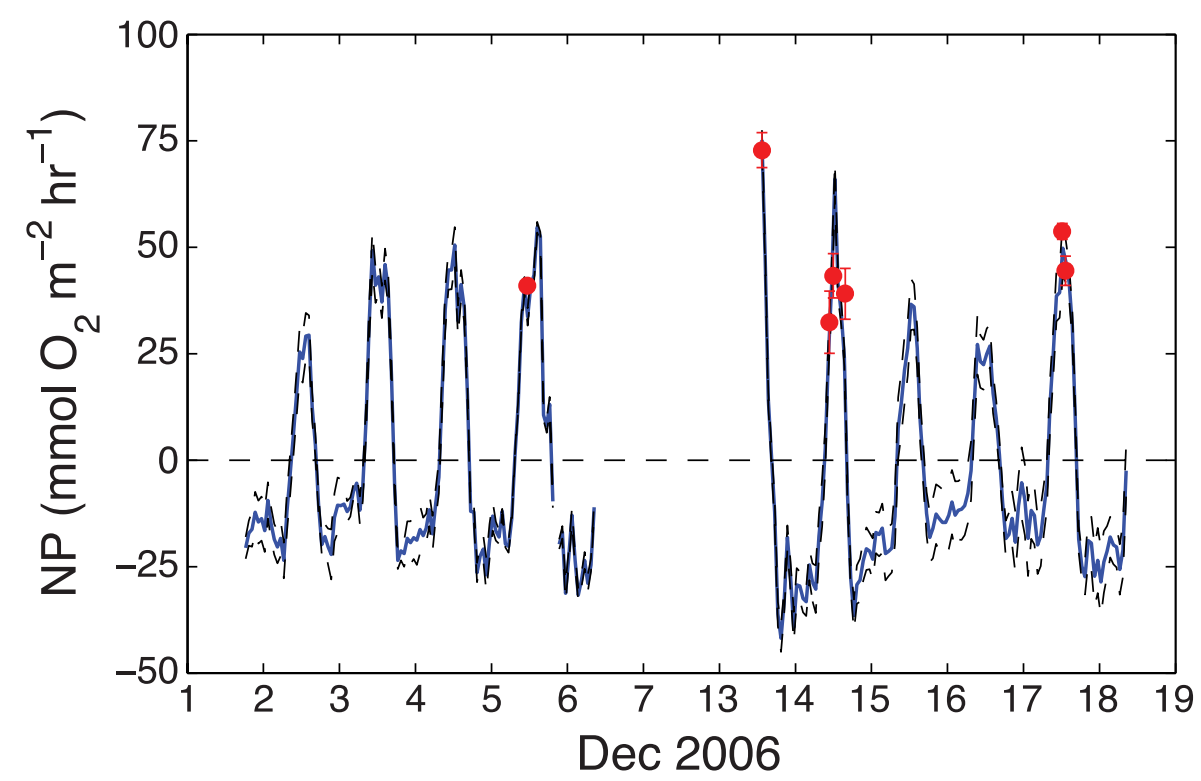

Figure 10. Calculated Net Production using the differential approach (blue line) \pm 1 std. error (dashed black line). Also shown are Lagrangian calculations of $N P$ (closed red circles) \pm 1 std. error (vertical bars).

profiles. Unfortunately, our ADCPs generally excluded $\sim 25 \mathrm{~cm}$ of the upper water column as a result of sidelobe interference near the free surface. Therefore we ran a numerical simulation of a current profile over the entire water column under average flow conditions using Delft3D (WL|Delft Hydraulics). The results of this simulation indicate that drifter speeds should exceed the depth-averaged current by $3 \mathrm{~cm} \mathrm{~s}^{-1}$ or $30 \%$ (Figure 13), thus explaining much of the discrepancy between observed $U_{d r}$ and $U_{E+S}$. Although physical modeling of the measured current pro-

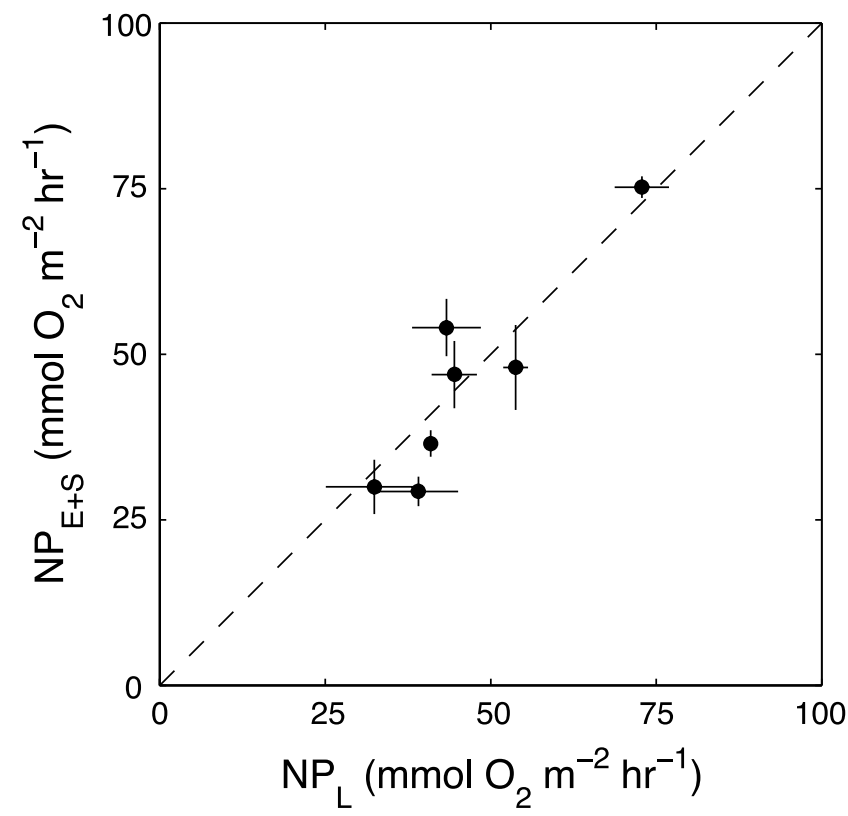

Figure 11. Eulerian calculations of Net Production versus Lagrangian calculations of Net Production (closed circles) \pm 1 std. error $\left(r^{2}=0.81, n=7\right)$. Dashed black line represents $1: 1$ relationship. files is beyond the scope of the present paper, our data indicate that the future use of drifters to estimate transport involve some examination of vertical structure in the current profiles.

[28] Because drifters capture only the upper part of the velocity profile, they move faster than the center of mass of a water parcel undergoing shear and thus do not reflect a true material derivative. Assuming a roughly constant gradient in dissolved oxygen (see section 2.4), the concentration at the site of the drifter should be higher in an

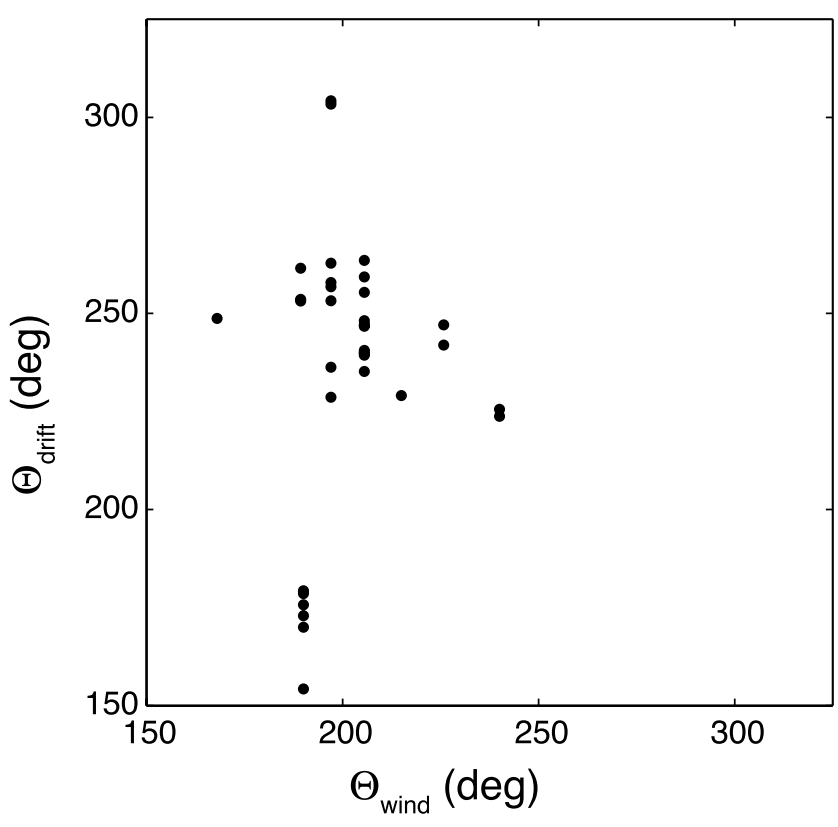

Figure 12. Direction of drifter propagation versus wind direction. There is no significant correlation $(r=0.13, p<$ $0.5, n=34)$. 


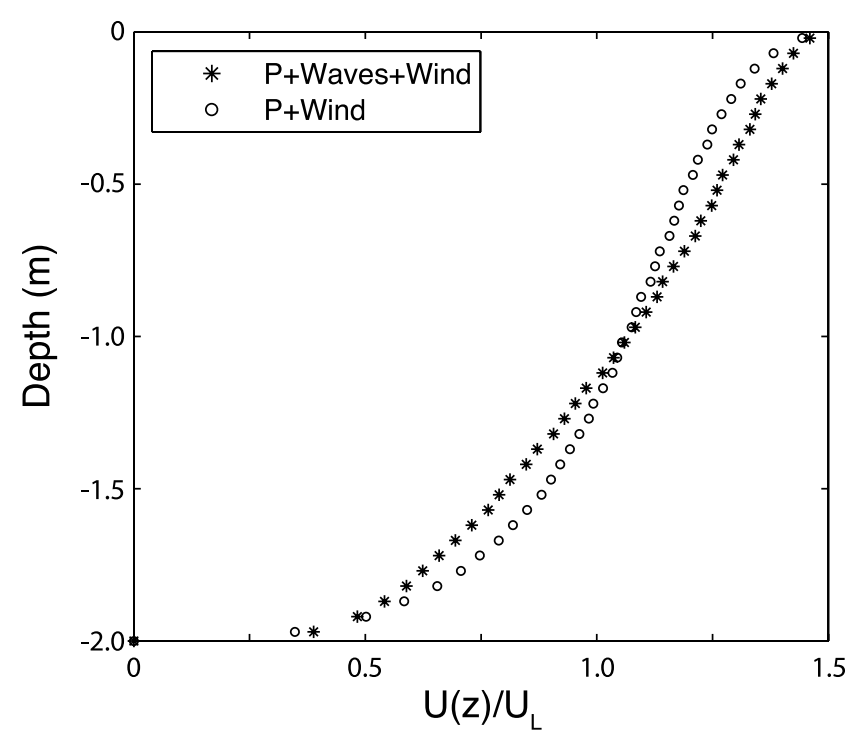

Figure 13. Current profiles over the reef flat simulated using Delft3D assuming a depth of $2 \mathrm{~m}$, a significant wave height of $0.4 \mathrm{~m}$, a wind speed of $5 \mathrm{~m} \mathrm{~s}^{-1}$, and a wind stress coefficient of 0.0013 such that the depth-averaged current $U_{E+S}$ is $10 \mathrm{~cm} \mathrm{~s}^{-1}$. Profiles shown include (1) the effects of a pressure gradient, waves and wind stress, and (2) the effects of a pressure gradient and wind stress without waves. In case \#1, the upper $80-\mathrm{cm}$ of the water column is moving $30 \%$ faster than the entire water column or $3 \mathrm{~cm} \mathrm{~s}^{-1}$. In case $\# 2$, the upper 80 -cm of the water column is moving $25 \%$ faster than the entire water column or $2.5 \mathrm{~cm} \mathrm{~s}^{-1}$.

amount proportional to the ratio of the streamwise distance traversed by the drifter $\left(\Delta s_{d r}\right)$ to that of the dye patch $\left(\Delta s_{d y}\right)$, or for an equal amount of time, the ratio of the speed of the drifter to that of the dye patch.

$$
\Delta C_{d r}=\Delta C_{d y} \frac{\Delta s_{d r}}{\Delta s_{d y}}=\Delta C_{L} \frac{U_{d r}}{U_{d y}} .
$$

[29] Thus if we had relied upon transport estimates from drifters alone in the present study, then we would have overestimated rates of Lagrangian NP by roughly $30 \%$ to $100 \%$ (Figure 7A). This is an important point given that many estimates of $N P, P$, and $R$ in the literature were based on tracking surface drifters and thus susceptible to such flow-dependent measurement errors. This suggests tracking dye is a much better approach for getting unbiased estimates of depth-averaged current speeds during the day; however, it would be extremely challenging to follow dye patches at night in order to get measurements of nighttime respiration. This represents an additional shortcoming of applying a Lagrangian approach to measure $N P$ to those mentioned earlier.

[30] The contribution of oxygen fluxes across the airwater interface to calculations of $N P$ during our study were trivial. Minor differences between wind speed-gas exchange relationships for coastal environments (where waveforms are generally steeper and shorter in wavelength) and for open ocean environments have been reported [Ho et al., 2006; Nightingale et al., 2000]. However, even though the waveforms over the reef flat may be steeper than under open ocean conditions, they were also considerably smaller in amplitude for a given wind speed, which would reduce surface wind drag relative to a fully developed sea. It is possible that bottom turbulence generated by wave stresses acting on the rough bottom of the reef flat could have provided an additional mechanism for enhanced gas exchange beyond wind stress alone [Upstill-Goddard, 2006]. Gas exchange velocities observed in wave-impacted coastal waters have deviated from wind speed based predictions by $5-10 \mathrm{~cm} \mathrm{~h}^{-1}$ due to differences in the dynamics controlling near-surface turbulent kinetic energy [Zappa et al., 2007]. These deviations are of the same scale as the average $k_{600}$ in this study of $\sim 5 \mathrm{~cm} \mathrm{~h}^{-1}\left(\max =21 \mathrm{~cm} \mathrm{~h}^{-1}\right)$. However, even tripling our present estimates of $k_{\mathrm{O} 2}$ increase our calculations of $N P$ by only 5 to $6 \%$. Thus despite the volatility of dissolved oxygen, gas exchange did not appear to be an important process governing its nonconservative behavior. In the future, however, it would be beneficial to explicitly measure gas transfer velocities across different reef communities.

[31] The integral approach grossly overestimated NP when compared against simultaneous Lagrangian measurements and other measurements reported in the literature. This is a numerical shortcoming of finding the difference between terms that are themselves the product of two large numbers: $q$ and $C$. Thus even small uncertainties in either $q$ or $C$ will lead to large discrepancies in the mass balance for the entire control volume. The differential approach of taking the vector product of the concentration gradient with a spatially averaged transport proved much more successful when compared with Lagrangian estimates of $N P$ (Figure 11). In addition, our data demonstrate that the contribution of dispersive fluxes acting on second-order concentration gradients were negligible and could be neglected (equation (5)). Nonetheless, they do indicate that neglecting this term likely results in an additional $\pm 1 \mathrm{mmol}$ $\mathrm{m}^{-2} \mathrm{~h}^{-1}$ of uncertainty in instantaneous estimates of $N P$, or $<2 \%$ of the signal amplitude.

[32] The size and shape of the control volume can be optimized for the particular current speeds, depth, and metabolic rate of a given setting. We expect the general goal of most control volume designs would be to find the minimum size in which a reliable concentration difference could be measured, thereby minimizing the effect of spatial patchiness in community structure on fluxes integrated across the control volume. The necessary length scale can be roughly estimated according to $L_{C V} \sim h \bar{U} \frac{\Delta C}{N P}$ where $\Delta C$ is the minimum desired measurable concentration difference of $\sim 10$ uM between oxygen sensors, or roughly three times the resolvable concentration difference $(\sim 3 \mathrm{uM})$. In the case of our study site, given minimum nighttime $N P$ of $\sim 25 \mathrm{mmol} \mathrm{m}^{-2} \mathrm{~h}^{-1}$ (since peak $\left|N P_{\text {dark }}\right|<$ peak $\left|N P_{\text {light }}\right|$ ), an average depth of $h \sim 1.7 \mathrm{~m}$, and a mean depth-averaged current of $U \sim 10 \mathrm{~cm} \mathrm{~s}^{-1}$, the necessary separation distance would then be $L_{C V} \sim 250 \mathrm{~m}$ or the approximate size of our control volume. This spatial scale is also comparable to the scale of community zonation typically observed over shallow reef flats [Kinsey, 1985]. It is important to note, however, that this is only a rough estimate given the complex relationship between the local and advective terms whose daily minima and maxima are out of phase (Figure 9). 
Nonetheless, it does provide a starting point from which to design future control volumes over other benthic communities. We cannot set an absolute limit for how shallow the reef community need to be for this approach to work, however, we expect that an upper threshold of 3-4 m would be appropriate. At depths greater than this, the effect the $N P$ signal would likely become too weak to reliably measure. Furthermore, high current speeds $\left(U>0.5 \mathrm{~m} \mathrm{~s}^{-1}\right)$ may also introduce additional limits to this approach through reducing the residence time of water parcels moving across the metabolically active areas of the reef.

[33] While daily $P: R$ ratios varied between 0.7 and 1.4 , $P: R$ ratios integrated over the first and second continuous $4-\mathrm{d}$ segments were 1.18 and 0.86 , respectively, indicating a shift from net production to net consumption over the period of study (Table 2). However, if the gap in the time series is neglected, then $P: R$ ratio was 1.01 when integrated over both segments indicating that short-term imbalances between community production and consumption occurring on the order of several days may not last very long (weeks or more). While these cursory results are consistent with prior observations within a closed reef mesocosm [Falter et al., 2001], additional data will need to be collected before we can make more general insights into the balance of production and respiration in shallow reef communities. The ability of our approach to monitor the net production or consumption of organic carbon for a given reef community ultimately depends upon the stability of the chemical sensors involved. We do not know what was the cause for the observed instrument drift; however, biofouling certainly could have played an important role as it usually does in undermining the stability of chemical and/or optical sensors moored in shallow, coastal waters. We cleaned the optode foils every other day in order to avoid problems of biofouling. If not corrected for properly, drift could greatly affect estimates of $N C P$ which at present are comparable in quality to estimates made by conventional Lagrangian methods. Nonetheless, our estimates of instantaneous $N P$ using the modified Eulerian approach agreed well with those made using the more conventional Lagrangian approach (Figure 11). We suggest that in the future this approach would be better applied with instruments able to auto-calibrate and/or autoclean their sensor every few days.

\section{Summary and Conclusions}

[34] The metabolism of organic carbon is ultimately responsible for driving additional important metabolic pathways such as calcification, nutrient uptake, and the synthesis of new tissue. The Eulerian approach presented here provides a means for continuously monitoring the overall metabolic activity of a reef community in terms of gross carbon fluxes with unprecedented temporal resolution. Although the Eulerian approach involves much greater up-front costs than the Lagrangian approach in terms of instrumentation, it involves much lower labor costs. This is an important practical point given that the cost of personnel can often greatly exceed that of equipment over the course of a project. We expect that this advantage will become even greater as physical and chemical instrumentation designed for nearshore environments become cheaper, more stable, and requires less maintenance. This should happen given that the development of increasingly stable and accurate sensors still remains an area of active research in both academic and private sectors due to increasing interest in the development of integrated ocean observing systems. Furthermore, the Eulerian approach provides continuous measurement of $N P$ with much greater temporal resolution than Lagrangian approaches allowing for the observation of changes in carbon metabolism occurring on the order of hours to days as well as a greater number of observations over a given period of time. It is certainly possible to use this approach with other combinations of sensors than those used here. One important application of this approach would be to observe short-term response of total community metabolism to acute stresses (e.g., high temperature, wave and storm damage, sediment loading, pollution, etc.), thus providing one means of quantifying their impact on reef communities. Thus toward a broader end, this approach could contribute to larger and longer-term studies of coral reef ecology at the community scale.

\begin{tabular}{|c|c|c|}
\hline Symbol & Description & Units \\
\hline$A_{C V}$ & Area of control volume & $\mathrm{m}^{2}$ \\
\hline$C$ & Dissolved oxygen concentration & $\mathrm{mmol} \mathrm{m}^{-3}$ \\
\hline$C_{e q}$ & $\begin{array}{l}\text { Equilibrium dissolved oxygen } \\
\text { concentration }\end{array}$ & $\mathrm{mmol} \mathrm{m}^{-3}$ \\
\hline$g$ & Acceleration due to gravity & $\mathrm{m} \mathrm{s}^{-2}$ \\
\hline h & Water depth & $\mathrm{m}$ \\
\hline$H$ & Wave height & $\mathrm{m}$ \\
\hline$J_{O 2}$ & Flux of dissolved oxygen & $\mathrm{mmol} \mathrm{m}{ }^{-2} \mathrm{hr}^{-1}$ \\
\hline$J_{D}$ & $\begin{array}{l}\text { Flux of dissolved oxygen due to } \\
\text { dispersion }\end{array}$ & $\mathrm{mmol} \mathrm{m}{ }^{-2} \mathrm{hr}^{-1}$ \\
\hline$J_{\text {gas }}$ & $\begin{array}{l}\text { Flux of dissolved oxygen across } \\
\text { air-sea interface }\end{array}$ & $\mathrm{mmol} \mathrm{m}{ }^{-2} \mathrm{hr}^{-1}$ \\
\hline$k$ & Wave number & $\mathrm{m}^{-1}$ \\
\hline$k_{600}$ & $\begin{array}{l}\text { Gas exchange coefficient for gas } \\
\text { with } \mathrm{Sc}=600\end{array}$ & $\mathrm{~cm} \mathrm{hr}^{-1}$ \\
\hline$k_{O 2}$ & $\begin{array}{l}\text { Dissolved oxygen gas exchange } \\
\text { coefficient }\end{array}$ & $\mathrm{cm} \mathrm{hr}^{-1}$ \\
\hline$K$ & Horizontal dispersion coefficient & $\mathrm{m}^{2} \mathrm{~s}^{-1}$ \\
\hline li & Length of side $i$ of the control volume & $\mathrm{m}$ \\
\hline$\ell$ & $\begin{array}{l}\text { Distance between drifters or dye } \\
\text { patch edges }\end{array}$ & $\mathrm{m}$ \\
\hline$n$ & Surface normal coefficient & \\
\hline$N C P$ & Daily Net Community Production & $\mathrm{mmol} \mathrm{m}^{-2} \mathrm{~d}^{-1}$ \\
\hline$N P$ & Net Production & $\mathrm{mmol} \mathrm{m}^{-2} \mathrm{hr}^{-1}$ \\
\hline$P$ & $\begin{array}{l}\text { Daily community gross primary } \\
\text { Production }\end{array}$ & $\mathrm{mmol} \mathrm{m}{ }^{-2} \mathrm{~d}^{-1}$ \\
\hline$P Q$ & Photosynthetic quotient & \\
\hline & Depth-integrated transport & $\mathrm{m}^{2} \mathrm{~s}^{-1}$ \\
\hline & Daily community Respiration & $\mathrm{mmol} \mathrm{m}^{-2} \mathrm{~d}^{-1}$ \\
\hline$R_{\text {dark }}$ & Average nighttime respiration & $\mathrm{mmol} \mathrm{m}^{-2} \mathrm{hr}^{-1}$ \\
\hline $\mathrm{Sc}_{\mathrm{O} 2}$ & $\begin{array}{l}\text { Schimdt number for dissolved } \\
\text { oxygen }\end{array}$ & \\
\hline$t$ & Time & $\mathrm{s}$ \\
\hline$U$ & Current speed & $\mathrm{cm} \mathrm{s}^{-1}$ \\
\hline$\theta$ & Current direction & $\operatorname{deg}$ \\
\hline Subscript & Description & \\
\hline$d r$ & Drifter & \\
\hline$d y$ & Dye & \\
\hline$E$ & Eulerian & \\
\hline$S$ & Stokes correction & \\
\hline$L$ & Lagrangian & \\
\hline$s$ & Position along current streamline & \\
\hline$t$ & $\begin{array}{l}\text { Axis transverse to current } \\
\text { streamline }\end{array}$ & \\
\hline$x$ & Cross-reef axis & \\
\hline$y$ & Along-reef axis & \\
\hline
\end{tabular}


[35] Acknowledgments. The authors would like to thank David Moreau and Eric Ash of the Marine Corp Base Hawaii for providing wind speed data and Pete Newkirk for assistance with fieldwork. This work was supported in part by grants OCE-0117859 and OCE 0452800 from the National Science Foundation.

\section{References}

Al-Horani, F. A., et al. (2003), The mechanism of calcification and its relation to photosynthesis and respiration in the scleractinian coral Galaxea fascicularis, Biol. Morya Vladivostok, 142, 419-426.

Anthony, K. R. N., et al. (2004), Temporal variation in light availability in coastal benthic habitats: Effects of clouds, turbidity and tides, Limnol. Oceanogr., 49, 2201-2211.

Anthony, K. R. N., et al. (2007), Bleaching, energetics, and coral mortality risk: Effects of temperature, light, and sediment regime, Limnol. Oceanogr., 52(2), 716-726.

Atkinson, M. J., and R. W. Grigg (1984), Model of a coral reef ecosystem. Part II: Gross and net benthic primary production at French Frigate Shoals, Hawaii, Coral Reefs, 3, 13-22.

Austin, J., and S. Atkinson (2004), The design and testing of small, lowcost GPS-tracked surface drifters, Estuaries, 27(6), 1026-1029.

Barnes, D. J., and M. J. Devereux (1984), Productivity and calcification on a coral reef: A survey using $\mathrm{pH}$ and oxygen electrodes, J. Exp. Mar. Biol. Ecol., 79, 213-231.

Broecker, W. S., and T.-H. Peng (1982), Tracers in the Sea, 690 pp., Eldigio Press, Lamont-Doherty Geol. Obs., Palisades, New York.

Callaghan, D. P., et al. (2006), Atoll lagoon flushing forced by waves, Coastal Eng., 53, 691-704.

Carpenter, R. C., and S. L. Williams (2007), Mass transfer limitation of photosynthesis of coral reef algal turfs, Biol. Morya Vladivostok, 151, $435-450$.

Chalker, B. E. (1981), Simulating light-saturation curves for photosynthesis and calcification by reef-building corals, Biol. Morya Vladivostok, 63, $135-141$.

Falter, J. L., et al. (2001), Production-respiration relationships at different time-scales within the biosphere 2 coral reef biome, Limnol. Oceanogr., 46(7), $1653-1660$.

Falter, J. L., et al. (2004), Mass transfer limitation of nutrient uptake by a wave-dominated reef flat community, Limnol. Oceanogr., 49, 18201831.

Fischer, H. B. (1979), Mixing in Inland Coastal Waters, 302 pp., Elsevier, Sydney.

Garcia, H. E., and L. I. Gordon (1992), Oxygen solubility in seawater: Better fitting equations, Limnol. Oceanogr, 37(6), 1307-1312.

Gattuso, J.-P., et al. (1993), Community metabolism and air-sea CO2 fluxes in a coral reef ecosystem (Moorea, French Polynesia), Mar. Ecol. Prog. Ser., 96, 259-267.

Gattuso, J.-P., et al. (1996), Carbon fluxes in coral reefs. part I: Lagrangian measurement of community metabolism and resulting air-sea $\mathrm{CO}_{2}$ disequilibrium, Mar. Ecol. Prog. Ser., 145, 109-121.

Genin, A., et al. (2002), Intense benthic grazing on phytoplankton in coral reefs revealed using the control volume approach, Oceanography, 15, $90-96$.

Goreau, T. F. (1959), The physiology of skeletal formation in corals. Part I: A method for measuring the rate calcium deposition by corals under different conditions, Biol. Bull., 116, 59-75.

Hearn, C. J., and I. N. Parker (1988), Hydrodynamic processes on the Ningaloo coral reef, Western Australia, paper presented at 6th Int Coral Reef Symp., ISRS (International Society for Reef Studies), Townsville, Australia.

Ho, D. T., et al. (2006), Measurements of air-sea gas exchange at high wind speeds in the Southern Ocean: Implications for global parameterizations, Geophys. Res. Lett., 33, L16611, doi:10.1029/2006GL026817.
Hoegh-Guldberg, O. (1999), Climate change, coral bleaching and the future of the world's coral reefs, Mar. Freshwater Res., 50(8), 839-866.

Hughes, T. P., et al. (2003), Climate change, human impacts, and the resilience of coral reefs, Science, 301(5635), 929-933.

Jahne, B., and C. Haussacker (1998), Air-water gas exchange, Ann. Rev. Fluid Mech., 92, 1937-1949.

Kenyon, K. E. (1969), Stokes drift for random gravity waves, J. Geophys. Res., 74(28), 6991-6994.

Kinsey, D. W. (1978), Productivity and calcification using slack-water periods and field enclosures, in Coral Reefs: Research Methods, edited by D. R. Stoddart and R. E. Johannes, pp. 439-468, UNESCO, Paris.

Kinsey, D. W. (1985), Metabolism, calcification, and carbon production: I. Systems level studies, paper presented at Fifth Int. Coral Reef Congress ISRS (International Society for Reef Studies), Tahiti, French Polynesia.

Lesser, M. P. (1996), Elevated temperatures and ultraviolet radiation cause oxidative stress and inhibit photosynthesis in symbiotic dinoflagellates, Limnol. Oceanogr., 41(2), 271-283.

List, J. E., et al. (1990), Diffusion and dispersion in coastal waters, J. Hydraul. Eng., 116(10), 1158-1179.

Lough, J. M., and D. J. Barnes (2000), Environmental controls on growth of the massive coral Porites, J. Exp. Mar. Biol. Ecol., 245, 225-243.

Lowe, R. J., et al. (2005), Spectral wave dissipation over a barrier reef, J. Geophys. Res., 110, C04001, doi:10.1029/2004JC002711.

Monismith, S. G., and D. A. Fong (2004), A note on the potential transport of scalars and organisms by surface waves, Limnol. Oceanogr., 49(4), $1214-1219$

Nightingale, P. D., et al. (2000), In-situ evaluation of air-sea gas exchange parameterizations using novel conservative and volatile tracers, Global Biogeochem. Cycles, 14(1), 373-387.

Odum, H. T., and E. P. Odum (1955), Trophic structure and productivity of a windward coral reef community on Eniwetok Atoll, Ecol. Monogr., 25(3), 1415-1444.

Plumb, R. A. (1979), Eddy fluxes of conserved quantities by small-amplitude waves, J. Atmos. Sci., 36, 1699-1706.

Sargent, M. A., and T. S. Austin (1949), Organic productivity of an atoll, Trans. Am. Geophys. Union, 30(2), 245-249.

Smith, S. V., and J. A. Marsh (1973), Organic carbon production on the windward reef flat of Eniwetok Atoll, Limnol. Oceanogr., 18(6), $953-961$.

Smith, S. V., and D. W. Kinsey (1978), Calcification and organic carbon metabolism as indicated by carbon dioxide, in Coral Reefs: Research Methods, edited by D. W. Stoddartm and R. E. Johannes, pp. 469-484, UNESCO, Paris.

Symonds, G., et al. (1995), Wave-driven flow over shallow reefs, J. Geophys. Res., 100(C2), 2639-2648.

Upstill-Goddard, R. C. (2006), Air-sea gas exchange in the coastal zone, Estuar. Coast. Shelf Sci., 70, 388-404.

Zappa, C. J., et al. (2007), Environmental turbulent mixing controls on airwater gas exchange in marine and aquatic systems, Geophys. Res. Lett., 34, L10601, doi:10.1029/2006GL028790.

M. J. Atkinson, J. L. Falter, and D. W. Schar, Hawaii Institute of Marine Biology, University of Hawaii, 46-007 Lilipuna Road, Kaneohe, HI 96744, USA. (falter@hawaii.edu)

R. J. Lowe, School for Environmental Systems Engineering, University of Western Australia, M015-32 Stirling Hwy, Crawley, WA 6009, Australia.

S. G. Monismith, Yamazaki Environment and Energy Building, Environmental Fluid Mechanics Laboratory, Stanford University, Stanford, 473 Via Ortega, Room 183, MC 4020, CA 94305, USA. 